\title{
Nanofabrication of a Solid-State, Mesoporous Nanoparticle Composite for Efficient Photocatalytic Hydrogen Generation
}

Yusuke Yamada, Hideyuki Tadokoro, Masood Naqshbandi, John Canning, Maxwell J. Crossley, Tomoyoshi Suenobu and Shunichi Fukuzumi

\begin{tabular}{|c|l|}
\hline Citation & ChemPlusChem, 81( 6): 521-525 \\
\hline Issue Date & 2016-06-16 \\
\hline Type & Journal Article \\
\hline Textversion & author \\
\hline & $\begin{array}{l}\text { This is the peer reviewed version of the following article: YAMADA, Y., } \\
\text { TADOKORO, H., NAQSHBANDI, M., CANNING, J., CROSSLEY, M. J., } \\
\text { SUENOBU, T., \& FUKUZUMI, S. (2016). Nanofabrication of a Solid-State, } \\
\text { Rights }\end{array}$ \\
$\begin{array}{l}\text { Mesoporous Nanoparticle Composite for Efficient Photocatalytic Hydrogen } \\
\text { Generation. ChemPlusChem. 81, 521-525. , which has been published in final form } \\
\text { at https://doi.org/10.1002/cplu.201600148 . This article may be used for } \\
\text { non-commercial purposes in accordance with Wiley Terms and Conditions for } \\
\text { Self-Archiving. }\end{array}$ \\
\hline DOI & \begin{tabular}{l} 
10.1002/cplu.201600148 \\
\hline
\end{tabular}
\end{tabular}

Self-Archiving by Author(s)

Placed on: Osaka City University Repository

YAMADA, Y., TADOKORO, H., NAQSHBANDI, M., CANNING, J., CROSSLEY, M. J., SUENOBU, T., \& FUKUZUMI, S. (2016). Nanofabrication of a Solid-State, Mesoporous Nanoparticle Composite for Efficient Photocatalytic Hydrogen Generation. ChemP/usChem. $81, \quad 521-525$. 


\title{
Nanofabrication of Solid-State, Mesoporous Nanoparticle Composite for Efficient Photocatalytic Hydrogen Generation**
}

\author{
Yusuke Yamada, *Hideyuki Tadokoro, Masood Naqshbandi, John Canning, * Maxwell J. \\ Crossley, * Tomoyoshi Suenobu, and Shunichi Fukuzumi*
}

\begin{abstract}
Room temperature self-assembly is used to fabricate a periodic array of uniformly sized $\mathrm{Al}^{3+}$-doped $\mathrm{SiO}_{2}$ nanoparticles (Al-SiO ${ }_{2} \mathrm{NPs}, 20-30 \mathrm{~nm}$ ). The uniform mesoporous structure is suitable for uniformly incorporating and distributing Pt nanoparticles (PtNPs), which are used as hydrogen evolution catalysts in artificial photosynthetic systems, without agglomeration during the catalytic reaction. When the surfaces of the Al-SiO ${ }_{2} \mathrm{NPs}$ are covered with an organic photocatalyst (2phenyl-4-(1-naphthyl)quinolinium ion, $\left.Q u P h^{+}-N A\right)$, each PtNP is surrounded by multiple $Q u P h^{+}-N A$ ions. The structure allows the PtNP to receive multiple electrons from $Q u P h^{\circ}-N A$ molecules, which are generated by reduction of the photoexcited state of $Q u P h^{+}-N A$ ions $\left(Q u P h^{\cdot}-N A^{\cdot+}\right)$ with $\beta$ dihydronicotinamide adenine dinucleotide $(N A D H)$, resulting in efficient photocatalytic $\mathrm{H}_{2}$ evolution.
\end{abstract}

Artificial photosynthesis attracts many researchers to realize an energy-sustainable society based on solar energy. ${ }^{[1-3]}$ For producing hydrogen $\left(\mathrm{H}_{2}\right)$ as a solar fuel, two different approaches have been developed. One is a heterogeneous approach in which semiconductors are used as photocatalysts. ${ }^{[4]}$ This type of catalyst

[*] Prof. Dr. Yusuke Yamada

Department of Applied Chemistry and Bioengineering,

Graduate School of Engineering, Osaka City University, Osaka 558-8585 (Japan)

E-mail: ymd@a-chem.eng.osaka-cu.ac.jp

Hideyuki Tadokoro, and Prof. Dr. Tomoyoshi Suenobu Department of Material and Life Science, Graduate School of Engineering, ALCA and SENTAN, Japan Science and Technology Agency (JST), Osaka University 2-1 Yamada-oka, Suita, Osaka 565-0871 (Japan)

Masood Naqshbandi, and Prof. Dr. Maxwell J. Crossley School of Chemistry, The University of Sydney, Sydney, New South Wales 2006 (Australia)

m.crossley@sydney.edu.au

Prof. Dr. John Canning

interdisciplinary Photonics Laboratories, School of Chemistry, The University of Sydney, Sydney,

New South Wales 2006 (Australia)

E-mail: john.canning@sydney.edu.au

Prof. Dr. Shunichi Fukuzumi

Department of Chemistry and Nano Science

Ewha Womans University, Seoul 120-750 (Korea)

Faculty of Science and Engineering, Meijo University, Nagoya, Aichi 468-0073 (Japan)

E-mail: fukuzumi@chem.eng.osaka-u.ac.jp

[**] This work was supported by ALCA and SENTAN projects from JST (to S.F.) and JSPS KAKENHI (Grant Nos. 24350069 and $15 \mathrm{~K} 14223$ to $Y . Y$.$) .$

Supporting information for this article is available on the WWW under http://www.angewandte.org or from the author. involves inherent problems with tuning the electronic bandgap suitable for visible light absorption. The other is a homogeneous approach using multiple components of light-harvesting, chargeseparation, and catalysis units, which can be developed and optimized separately. ${ }^{[5-13]}$ This approach allows the use of various types of photosensitizers, which absorb visible light, with metal nanoparticles (MNPs) such as PtNPs as $\mathrm{H}_{2}$-evolution catalysts. Among models mimicking light harvesting and charge-separation units, ${ }^{[14-16]}$ a class of donor-acceptor linked cation molecules such as 2-phenyl-4-(1-naphthyl)quinolinium ion $\left(\mathrm{QuPh}^{+}-\mathrm{NA}\right.$, Scheme 1a $)^{[16]}$ have been reported to afford an extremely long-lived electron-transfer (ET) state with high oxidation and reduction abilities under photoirradiation. $\mathrm{QuPh}^{+}-\mathrm{NA}$ successfully acts as an organic a)

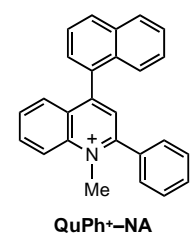

c) $\mathrm{Al}-\mathrm{SiO}_{2} \mathrm{NPs}$ assembly

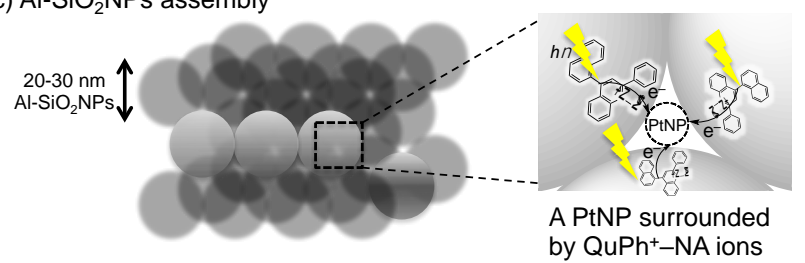

Scheme 1. a) Chemical structure of $\mathrm{QuPh}^{+}-\mathrm{NA}$ ion, b) overall photocatalytic cycle of the $\mathrm{H}_{2}$-evolution system and c) catalytic structure prepared by mixing and dried silica-alumina nanoparticles (Al$\mathrm{SiO}_{2} \mathrm{NPS}$ ) supporting QuPh ${ }^{+}-\mathrm{NA}$ on silica-alumina and PtNPs.

photocatalyst for efficient photocatalytic $\mathrm{H}_{2}$ evolution together with PtNPs and $\beta$-dihydronicotinamide adenine dinucleotide (NADH) in solution. ${ }^{[17-19]}$ As indicated in Scheme 1b, photoexcited $\mathrm{QuPh}^{+}-\mathrm{NA}\left(\mathrm{QuPh}^{\circ}-\mathrm{NA}^{-+}\right)$reacts with $\mathrm{NADH}$ to form $\mathrm{QuPh}^{-}$ NA, which injects an electron to PtNPs for $\mathrm{H}_{2}$ evolution. ${ }^{[17-19]}$ The long lifetime of the ET state resulted in elimination of an electron relay, which is usually a necessary component of photocatalytic $\mathrm{H}_{2}$-evolution systems for elongation of the lifetime of the chargeseparated state.

The lifetime of the ET states of $\mathrm{QuPh}^{+}-\mathrm{NA}$ generated by photoirradiation can be further elongated $(\tau>20 \mathrm{~s}$ ) by being loaded on silica-alumina, where a $\mathrm{QuPh}^{+}-\mathrm{NA}$ molecule cannot interact with any other molecule. ${ }^{[20]}$ Additionally, the loading of PtNPs on silica-alumina can be expected to suppress deactivation and agglomeration or clustering of PtNPs during a reaction. ${ }^{[21]}$ However, conventional silica-alumina loading $\mathrm{QuPh}^{+}-\mathrm{NA}$ and $\mathrm{PtNPs}$ exhibited only moderate catalytic activity, ${ }^{[22]}$ mainly because of a disordered structure unsuitable for multiple electron reduction. Each PtNP should be surrounded by multiple $\mathrm{QuPh}^{+}-\mathrm{NA}$ ions on a support for more efficient photocatalytic $\mathrm{H}_{2}$ evolution. 
Recently, room temperature self-assembly of monodispersed $\mathrm{SiO}_{2}$ nanoparticles $(20-30 \mathrm{~nm})$ has been reported to form a densely packed monolithic structure with discrete mesospaces $(2-6 \mathrm{~nm})$ among the particles by convective flow through evaporation. ${ }^{[23]}$ This assembly contains discrete and uniform mesospaces, which can stably incorporate not only various organic molecules including organic dyes such as Rhodamine $\mathrm{B}$, zinc porphyrins ${ }^{[24]}$ but also enzymes. ${ }^{[25]}$ The discrete mesospaces of the assembly act as molecular sieves and aggregation and clustering of incorporated PtNPs will be strongly avoided. Additionally, an ideal catalytic ensemble for photocatalytic $\mathrm{H}_{2}$ evolution can be obtained when a single PtNP is incorporated in a discrete mesospace, and the wall of the mesospace is decorated by the $\mathrm{QuPh}^{+}-\mathrm{NA}$ ions (Scheme 1c). The self-assembly of the $\mathrm{SiO}_{2}$ nanoparticles using as the support assures the high dispersion and uniform catalytic ensemble formation in the mesospaces. However, PtNPs and $\mathrm{QuPh}^{+}-\mathrm{NA}$ have yet to be incorporated into the assembly.

We report herein the construction of self-assembled structures of size-controlled Pt nanoparticles (PtNPs) capped with polyvinyl pyrrolidone (PVP) and $\mathrm{Al}^{3+}$-doped $\mathrm{SiO}_{2}$ nanoparticles uniform in size $20-30 \mathrm{~nm}\left(\mathrm{Al}-\mathrm{SiO}_{2} \mathrm{NPs}\right)$ incorporating $\mathrm{QuPh}^{+}-\mathrm{NA}$ for the efficient photocatalytic $\mathrm{H}_{2}$ evolution using $\mathrm{NADH}$ as a sacrificial electron donor. Doping of $\mathrm{Al}^{3+}$ ions to $\mathrm{SiO}_{2}$ generates cation exchange sites at the surfaces, where cationic $\mathrm{QuPh}^{+}-\mathrm{NA}$ can be stably adsorbed. The PtNPs capped with PVP have been reported to act as an efficient $\mathrm{H}_{2}$-evolution catalyst in homogeneous reaction systems. ${ }^{[19 a]}$ The cracked structure of the assembly seems to be advantageous for diffusion of NADH inside the whole volume of the structure.

$\mathrm{Al}-\mathrm{SiO}_{2} \mathrm{NPs}$ were prepared by surface alumination of $\mathrm{SiO}_{2}$ nanoparticles with $\mathrm{NaAlO}_{2}$ in an aqueous dispersion. To the aqueous dispersion of $\mathrm{Al}-\mathrm{SiO}_{2} \mathrm{NPs}$, an acetonitrile solution of $\mathrm{QuPh}^{+}-\mathrm{NA}$ and an aqueous suspension of PtNPs ( 2 $\left.\mathrm{nm}\right)$ capped with PVP were added successively and placed on an ultrasound sonicator for $30 \mathrm{~min}$. The mixture was then dropped on a glass substrate to form the catalytic structures by slow evaporation in air at room temperature. Figure 1a shows the photograph of obtained black fibers. Thermogravimetric analysis suggested that the catalytic structures incorporated almost all $\mathrm{QuPh}^{+}-\mathrm{NA}$ in the dispersion (Figure $\mathrm{S} 1 \uparrow$ ). The self-assembled structure of PtNPs and $\mathrm{Al}-\mathrm{SiO}_{2} \mathrm{NPs}$ was confirmed by TEM measurements as shown in Figure $1 \mathrm{~b}$, in which many mesospaces among $\mathrm{Al}-\mathrm{SiO}_{2} \mathrm{NPs}$ are observed. Incorporation and distribution of PtNPs in the discrete mesospaces were confirmed in the expanded view (Figure 1b, inset). The size uniformity of the mesospaces in the assembly was confirmed by $\mathrm{N}_{2}$ adsorption-desorption isotherms measurement at $77 \mathrm{~K}$ (Figure 1c), which is a method used previously in combination with atomic force microscopy to confirm that it is uniform throughout the volume of the structure. ${ }^{[23]}$ The isotherm is clearly classified to type IV, indicating the presence of mesoporous structure. ${ }^{[26]}$ The pore size distribution calculated from the adsorption branch of the isotherms by the Barrett-Joyner-Halenda (BJH) method, which assumes a cylindrical pore model, was determined to be $R=\sim 6 \mathrm{~nm}$ with a Brunauer-Emmett-Teller (BET) surface area as low as $132 \mathrm{~m}^{2} \mathrm{~g}^{-1}$ (Figure 1d). Although the mesospaces in the structure are not the cylindrical pore assumed in the $\mathrm{BJH}$ model, the narrower pore size distribution assures the uniformity of the mesospaces in size. The relatively small surface area in spite of the mesoporous structure allows $\mathrm{QuPh}^{+}-\mathrm{NA}$ at low concentrations to almost fully cover the surfaces of the $\mathrm{Al}-\mathrm{SiO}_{2} \mathrm{NPs}$, in which each PtNP in a mesospace easily interacts with multiple $\mathrm{QuPh}^{+}-\mathrm{NA}$ ions adsorbed on $\mathrm{Al}-\mathrm{SiO}_{2} \mathrm{NPs}$. It also prevents clustering and aggregation that will deleteriously impact electron transfer in the photoresponse involved with catalysis.

Photoresponse of $\mathrm{QuPh}^{+}-\mathrm{NA}$ adsorbed on $\mathrm{Al}-\mathrm{SiO}_{2} \mathrm{NPs}$ was examined by EPR measurements before the catalytic activity measurements, because the high density of $\mathrm{QuPh}^{+}-\mathrm{NA}$ may
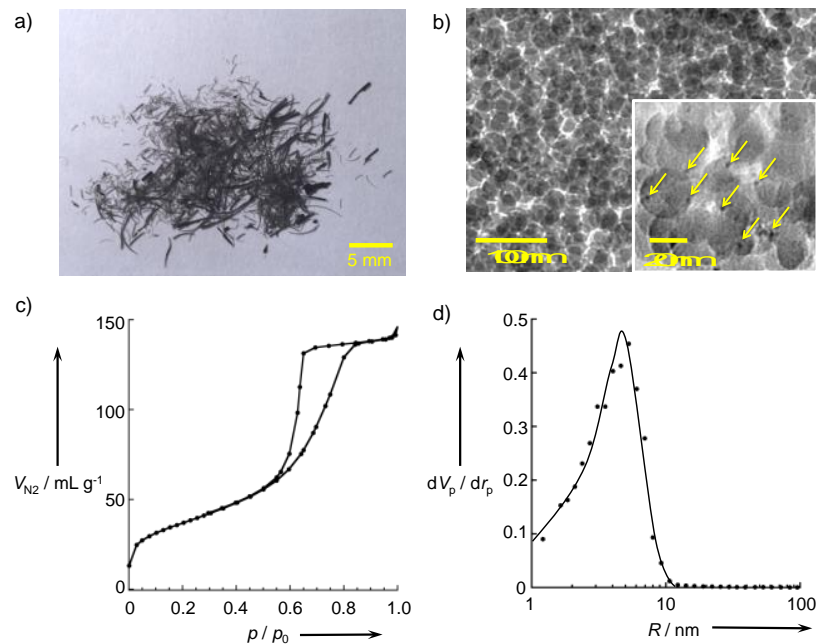

Figure 1. a) A photograph of the catalytic structure of $\mathrm{Al}-\mathrm{SiO}_{2} \mathrm{NPs}$ incorporating PtNPs and $\mathrm{QuPh}^{+}-\mathrm{NA}$. b) A transmission electron microscope (TEM) image of the catalytic structures. (The arrows point PtNPs.) c) $\mathrm{N}_{2}$ adsorption-desorption isotherms of the catalytic structure at $77 \mathrm{~K}\left(V_{\mathrm{N} 2}\right.$ : volume of adsorbed $\left.\mathrm{N}_{2} \mathrm{~mL} \mathrm{mg}^{-1}\right)$. d) Pore radius $(R)$ distribution calculated from the adsorption branch of the isotherm using the Barrett-Joyner-Halenda (BJH) method.

promote intermolecular back electron transfer, which shortens the lifetime of the ET state (Figure 2). ${ }^{[16]} \mathrm{Al}_{-} \mathrm{SiO}_{2} \mathrm{NPs}$ incorporating $\mathrm{QuPh}^{+}-\mathrm{NA}\left(\mathrm{QuPh}^{+}-\mathrm{NA} / \mathrm{Al}-\mathrm{SiO}_{2} \mathrm{NPs}\right)$ was prepared by the same procedure used for $\mathrm{PtNPs} / \mathrm{QuPh}^{+}-\mathrm{NA} / \mathrm{Al}-\mathrm{SiO}_{2} \mathrm{NPs}$ but without PtNPs. Photoirradiation of $\mathrm{QuPh}^{+}-\mathrm{NA} / \mathrm{Al}-\mathrm{SiO}_{2} \mathrm{NPs}$ with a 1000 W high-pressure $\mathrm{Hg}$ lamp through a UV-band rejection filter (transmission: $\lambda>340 \mathrm{~nm}$ ) leads to the formation of the ET state $\left(\mathrm{QuPh}^{\circ}-\mathrm{NA}^{*+}\right)$ via photoinduced electron transfer from the naphthalene (NA) moiety to the singlet excited state of the quinolinium a)
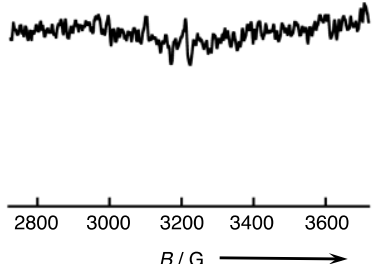

c)

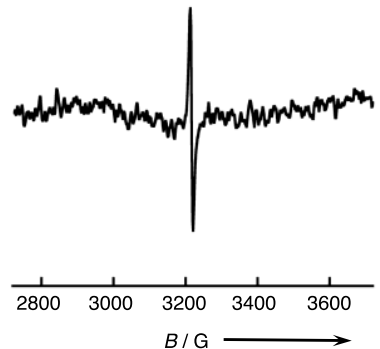

b)

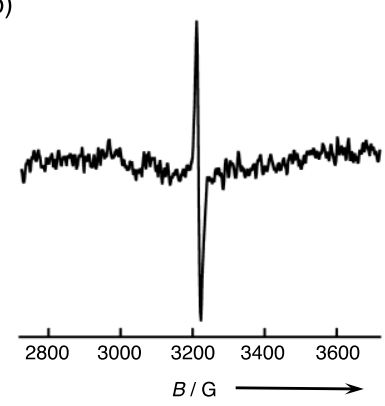

d)

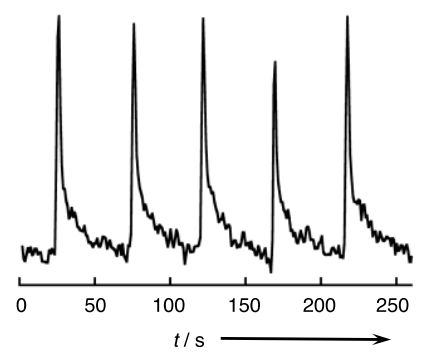

Figure 2. EPR spectra of $\mathrm{QuPh}^{+}-\mathrm{NA} / \mathrm{Al}-\mathrm{SiO}_{2} \mathrm{NPs}$ (a) in the dark (dry conditions), (b) under illumination $(\lambda>340 \mathrm{~nm}$, dry conditions) and (c) under illumination ( $\lambda>340 \mathrm{~nm}$, wet conditions). (d) Time $(t)$ course of EPR signal intensity of $\mathrm{QuPh}^{+}-\mathrm{NA} / \mathrm{Al}-\mathrm{SiO}_{2} \mathrm{NPs}$ (wet conditions) under intermittent illumination (light on, $2 \mathrm{sec}$ and light off $48 \mathrm{sec}, \lambda>340 \mathrm{~nm}$, wet conditions). ( $B$ : magnetic field) 
ion $\left(\mathrm{QuPh}^{+}\right)$moiety. The evidence is the EPR signal appearing at $g=2.0031$ (Figure 2b), ${ }^{[20]}$ which was not observed before the photoirradiation (Figure 2a). Water vapor was introduced to the sample at $313 \mathrm{~K}$ to examine the effect of water on the formation of the ET state. Appearance of the EPR signal under photoirradiation suggests that the ET state forms in the presence of water. Photorobustness of the $\mathrm{QuPh}^{+}-\mathrm{NA}$ was confirmed by similar peak intensities at repetitive intermittent photoirradiation $\mathrm{ON}$ for $2 \mathrm{~s}$ followed by $48 \mathrm{~s}$ OFF in the dark (Figure 2d).

Photocatalytic $\mathrm{H}_{2}$ evolution was examined under photoirradiation $(\lambda>340 \mathrm{~nm})$ of a phthalate buffer $(\mathrm{pH} 4.5,2.0 \mathrm{~mL})$ containing the catalytic structure $\left(\mathrm{PtNPs} / \mathrm{QuPh}^{+}-\mathrm{NA} / \mathrm{Al}-\mathrm{SiO}_{2} \mathrm{NPs}, 5.0\right.$ $\mathrm{mg}$; PtNPs, $0.20 \mu \mathrm{mol}_{-\mathrm{Pt}}$; $\left.\mathrm{QuPh}^{+}-\mathrm{NA}, 1.1 \mu \mathrm{mol}\right)$ and NADH $(1.0$ $\mathrm{mM})$ at room temperature. The catalytic structure was granulated by magnetic stirring for high dispersion in water before the catalysis measurements. As indicated in Figure 3 (red circle), $\mathrm{H}_{2}$ evolution lasted for more than $40 \mathrm{~h}$ by the successive addition of a condensed aqueous NADH solution to the reaction solution after $\mathrm{H}_{2}$ evolution ceased. The yields of evolved $\mathrm{H}_{2}$ based on the

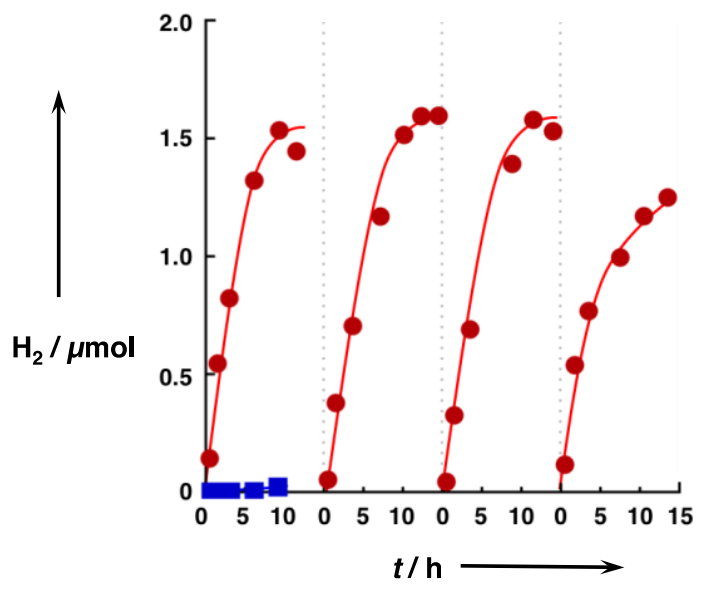

Figure 3. Time $(t)$ courses of $\mathrm{H}_{2}$ evolution under photoirradiation $(\lambda$ $>340 \mathrm{~nm}$ ) of a de-aerated dispersion $(2.0 \mathrm{~mL})$ of a phthalate buffer $(\mathrm{pH} 4.5)$ containing the catalytic structure (PtNPs/QuPh ${ }^{+}-\mathrm{NA} / \mathrm{Al}-$ $\mathrm{SiO}_{2} \mathrm{NPs}, 5.0 \mathrm{mg}$; Pt, $0.20 \mu \mathrm{mol}-\mathrm{Pt}$; QuPh${ }^{+}-\mathrm{NA}, 1.1 \mu \mathrm{mol}$, red circle) or conventional mesoporous silica-alumina supporting $\mathrm{QuPh}^{+}-$ NA (5.0 mg, [QuPh ${ }^{+}-\mathrm{NA}$ ]: $1.1 \mu \mathrm{mol}$, blue square), PtNPs (Pt: 0.20 $\mu \mathrm{mol})$ and $\mathrm{NADH}(1.0 \mathrm{mM})$. An aliquot $(100 \mu \mathrm{L})$ of an NADH solution $(20 \mathrm{mM})$ was added to the reaction solution after $\mathrm{H}_{2}$ evolution ceased.

amount of NADH were $76,80,79$ and $63 \%$ for each run. The initial $(t<3 \mathrm{~h}) \mathrm{H}_{2}$-evolution rates normalized by the catalyst weight were $\mathrm{d}\left(\mathrm{H}_{2}\right) / \mathrm{d} t=54,44,46$ and $52 \mu \mathrm{molh}^{-1} \mathrm{~g}_{\text {-cat }}{ }^{-1}$. No obvious structural change was observed by TEM for the catalytic structure after repetitive reactions (Figures S2 and S3†). The weight of PtNPs in the reaction suspension was $0.20 \mu \mathrm{mol} \times 195$ $\mathrm{g} \mathrm{mol}^{-1}=39 \mu \mathrm{g}$. The mol number of Pt atoms locating on the surfaces of the PtNPs with the size of $2 \mathrm{~nm}$ has been reported as $2.8 \times 10^{-3} \mathrm{~mol} \mathrm{~g}_{-\mathrm{Pt}}{ }^{-1}{ }^{[17 \mathrm{~b}]}$ Thus, the total number of surface Pt atoms is $1.1 \times 10^{-7}$ mol. The total mol number of evolved $\mathrm{H}_{2}$ with $\mathrm{PtNPs} / \mathrm{QuPh}^{+}-\mathrm{NA} / \mathrm{Al}-\mathrm{SiO}_{2} \mathrm{NPs}$ was $6.0 \mu \mathrm{mol}$, indicating that the turnover number of $\mathrm{H}_{2}$ evolution per surface $\mathrm{Pt}$ atom was 55 . Nearly stoichiometric amount of $\mathrm{H}_{2}$ was evolved when the loading amount of PtNPs in the catalytic structure was increased to $0.40 \mu \mathrm{mol}_{-\mathrm{Pt}}$ with $\mathrm{QuPh}^{+}-\mathrm{NA}(0.80 \mu \mathrm{mol})$ (Figure $\left.\mathrm{S} 4 \dagger\right)$. On the other hand, negligible amount of $\mathrm{H}_{2}$ was evolved for the photocatalytic reaction system using the PtNPs and conventional mesoporous silica-alumina incorporating $\mathrm{QuPh}^{+}-\mathrm{NA}$ instead of $\mathrm{PtNPs} / \mathrm{QuPh}^{+}-\mathrm{NA} / \mathrm{Al}-\mathrm{SiO}_{2} \mathrm{NPs}$ under the same reaction conditions (Figure 2, blue square). ${ }^{[22]}$ The very low $\mathrm{H}_{2}$ yield resulted from the size of the PtNPs $(\sim 2 \mathrm{~nm})$, which is too large to access photoexcited $\mathrm{QuPh}^{+}-\mathrm{NA}$ incorporated inside the cylindrical mesopores, and the larger surface area unsuitable for close location of PtNPs and $\mathrm{QuPh}^{+}-\mathrm{NA}$. However, when the same amount of $\mathrm{QuPh}^{+}-\mathrm{NA}, \mathrm{PtNPs}$ and NADH were used in a homogeneous system using a mixed solvent of phthalate buffer ( $\mathrm{pH} 4.5)$ and $\mathrm{MeCN}$ [1:1 (v/v)], the stoichiometric amount of $\mathrm{H}_{2}$ based on the used amount of NADH as a sacrificial electron donor evolved within 2 min. ${ }^{[19 a]}$ Thus, photocatalytic activity of $\mathrm{PtNPs} / \mathrm{QuPh}^{+}-\mathrm{NA} / \mathrm{Al}-$ $\mathrm{SiO}_{2} \mathrm{NPs}$ was decreased for $\mathrm{H}_{2}$ evolution although no organic solvent is necessary.

The photocatalytic $\mathrm{H}_{2}$ evolution was also investigated under photoirradiation of a phthalate buffer $(\mathrm{pH} 4.5)$ containing PtNPs $\left(0.20 \mu \mathrm{mol}_{-\mathrm{Pt}}\right), \mathrm{QuPh}^{+}-\mathrm{NA} / \mathrm{Al}-\mathrm{SiO}_{2} \mathrm{NPs}\left(5.0 \mathrm{mg} ; \mathrm{QuPh}^{+}-\mathrm{NA}, 1.1\right.$ $\mu \mathrm{mol})$, and NADH $(1.0 \mathrm{mM})$ to confirm the catalytic activity originates from the fully pre-assembled structure. A certain amount of $\mathrm{H}_{2}$ evolution was observed for $6 \mathrm{~h}$ with $\mathrm{d}\left(\mathrm{H}_{2}\right) / \mathrm{d} t=20$ $\mu \mathrm{mol} \mathrm{h}{ }^{-1} \mathrm{~g}_{\text {-cat }}{ }^{-1}$ (Figure 4, blue square), which is less than half that for fully pre-assembled PtNPs/QuPh ${ }^{+}-\mathrm{NA} / \mathrm{Al}-\mathrm{SiO}_{2} \mathrm{NPs}$ (Figure 4, red circle), with $33 \% \mathrm{H}_{2}$ yield. At $2^{\text {nd }}$ run, no increase in the $\mathrm{H}_{2}$

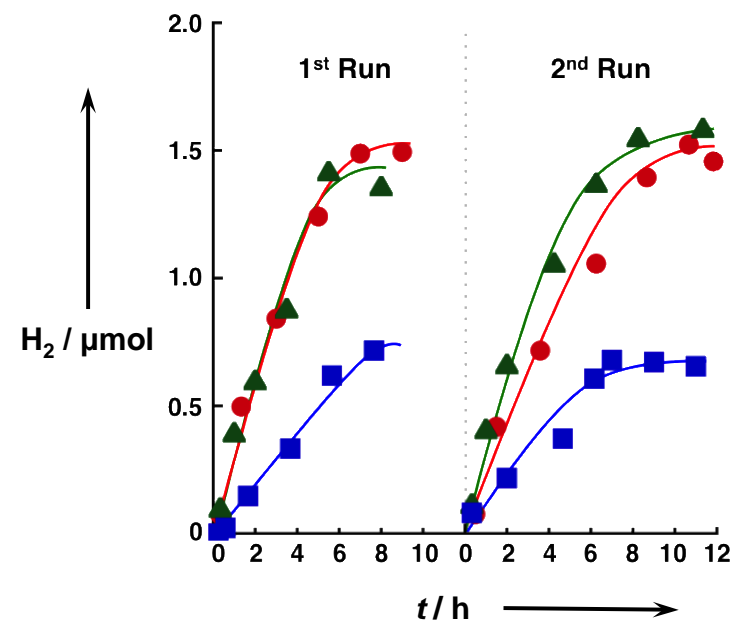

Figure 4. Effect of preparation methods of the catalyst structure on photocatalytic $\mathrm{H}_{2}$ evolution. Time $(t)$ courses of $\mathrm{H}_{2}$ evolution under photoirradiation $(\lambda>340 \mathrm{~nm})$ of a de-aerated dispersion $(2.0 \mathrm{~mL})$ of a phthalate buffer $(\mathrm{pH} 4.5)$ containing NADH (1.0 mM), QuPh ${ }^{+}$ $\mathrm{NA} / \mathrm{Al}-\mathrm{SiO}_{2} \mathrm{NPs}$ and a $\mathrm{Pt}$ catalyst $\left[\mathrm{K}_{2} \mathrm{PtCl}_{6}\right.$ (green triangle) and PtNPs (blue square)]. Red circles are the data obtained for the fully preassembled PtNPs/QuPh ${ }^{+}-\mathrm{NA} / \mathrm{Al}-\mathrm{SiO}_{2} \mathrm{NPs}$ for comparison.

yield was observed with a slightly lower $\mathrm{H}_{2}$-evolution rate $\left(\mathrm{d}\left(\mathrm{H}_{2}\right) / \mathrm{d} t=14 \mu \mathrm{mol} \mathrm{h}^{-1} \mathrm{~g}_{\text {-cat }}^{-1}\right)$. The lower $\mathrm{H}_{2}$ yields suggest that PtNPs in the solution were hardly accessible to some $\mathrm{QuPh}^{+}-\mathrm{NA}$ molecules located deeply inside the assembly. However, the $\mathrm{H}_{2}$ yields are significantly high compared with that for the reaction system using the conventional mesoporous silica-alumina as a platform for $\mathrm{QuPh}^{+}-\mathrm{NA}$ (Figure 3, blue square). The larger pore diameter and the cracked structure of $\mathrm{QuPh}^{+}-\mathrm{NA} / \mathrm{Al}-\mathrm{SiO}_{2} \mathrm{NPs}$ allow large PtNPs to penetrate inside the assembly.

PtNPs can be in situ prepared by reduction of $\mathrm{K}_{2} \mathrm{PtCl}_{6}$, which is accessible to all $\mathrm{QuPh}^{+}-\mathrm{NA}$ ions loaded on the $\mathrm{Al}-\mathrm{SiO}_{2}$ assembly, by utilizing photocatalysis of the $\mathrm{QuPh}^{+}-\mathrm{NA}$ ions under conditions for the photocatalytic $\mathrm{H}_{2}$ evolution. ${ }^{[22]}$ The photocatalytic $\mathrm{H}_{2}$ evolution conducted with the catalytic structure of $\mathrm{QuPh}^{+}-\mathrm{NA} / \mathrm{Al}-$ $\mathrm{SiO}_{2} \mathrm{NPs}$ in an aqueous phthalate buffer containing $\mathrm{K}_{2} \mathrm{PtCl}_{6}$ resulted in $\mathrm{H}_{2}$ yields based on the amount of NADH of 71 and $73 \%$ with $\mathrm{d}\left(\mathrm{H}_{2}\right) / \mathrm{d} t=46$ and $46 \mu \mathrm{mol} \mathrm{h}^{-1} \mathrm{~g}_{\text {-cat }}{ }^{-1}$ in the repetitive experiments (Figure 4, green triangle). The slightly lower $\mathrm{H}_{2}$ yield in $1^{\text {st }}$ run compared to that in $2^{\text {nd }}$ run resulted from the reduction of the $\mathrm{K}_{2} \mathrm{PtCl}_{6}$ to PtNPs only in the $1^{\text {st }}$ run. The formation of PtNPs after the photocatalytic reactions was confirmed by TEM observation for the catalyst after $\mathrm{H}_{2}$ evolution (Figure $\mathrm{S} 3 \dagger$ ). No particles that 
have grown larger than $5 \mathrm{~nm}$ was observed because of the size limitation in the mesospaces. The similar $\mathrm{H}_{2}$-evolution rates for the reaction systems using fully pre-assembled $\mathrm{PtNPs} / \mathrm{QuPh}^{+}$ $\mathrm{NA} / \mathrm{Al}-\mathrm{SiO}_{2} \mathrm{NPs}$ (Figure 4, red circles) and $\mathrm{QuPh}^{+}-\mathrm{NA} / \mathrm{Al}-$ $\mathrm{SiO}_{2} \mathrm{NPs}$ and $\mathrm{K}_{2} \mathrm{PtCl}_{6}$ in the $2^{\text {nd }}$ run suggest that PVP used as an organic capping agent for PtNPs little influenced the catalysis of PtNPs for $\mathrm{H}_{2}$ evolution.

In summary, we have successfully self-assembled an active catalytic structure of $\mathrm{QuPh}^{+}-\mathrm{NA}$ and PtNPs for photocatalytic $\mathrm{H}_{2}$ evolution utilizing uniformly distributed mesospaces among Al$\mathrm{SiO}_{2} \mathrm{NPs}$ at room temperature. The mesospaces allowed the controlled incorporation of PtNPs surrounded by multiple $\mathrm{QuPh}^{+}-\mathrm{NA}$ ions. These cannot be well ordered in conventional mesoporous silica-alumina. Self-assembled structures of such metal-oxide nanoparticles are a promising platform to assemble functional organic compounds and nanoparticles.

\section{Experimental Section}

All chemicals used for synthesis were obtained from chemical companies and used without further purification. $\mathrm{Al}-\mathrm{SiO}_{2} \mathrm{NPs}$ were prepared by surface alumination of silica nanoparticles with sodium aluminate at room temperature. $\mathrm{PtNPs} / \mathrm{QuPh}^{+}-\mathrm{NA} / \mathrm{Al}-\mathrm{SiO}_{2} \mathrm{NPs}$ was prepared by slow evaporation of a mixed dispersion containing PtNPs, QuPh ${ }^{+}-\mathrm{NA}$ and $\mathrm{Al}-\mathrm{SiO}_{2} \mathrm{NPs}$. A typical procedure for photocatalytic $\mathrm{H}_{2}$ evolution is as follows: a dispersion $(1.5 \mathrm{~mL})$ of a phthalate buffer $(50 \mathrm{mM}, \mathrm{pH} 4.5)$ containing PtNPs/QuPh ${ }^{+}-\mathrm{NA} / \mathrm{Al}-$ $\mathrm{SiO}_{2} \mathrm{NPs}$ [5.0 mg, QuPh${ }^{+}-\mathrm{NA}(0.22 \mathrm{mM})$, [Pt]: $0.05 \mathrm{mM}$ ] was magnetically stirred for $3 \mathrm{~h}$ in dark. Then, a phthalate buffer containing $\mathrm{NADH}(4.0 \mathrm{mM}, 0.5 \mathrm{~mL})$ was added to the dispersion and flushed with $\mathrm{N}_{2}$ gas for 10 min before photoirradiation. The solution was then irradiated for a certain time with a xenon lamp (Ushio Optical, Model X SX-UID 500X AMQ) through a filter (Asahi Techno Glass L39) transmitting $\lambda>340 \mathrm{~nm}$ at room temperature. The gas in a headspace was analyzed by a gas chromatograph to determine the amount of evolved $\mathrm{H}_{2}$. The experimental details are described in the Supporting Information.

\section{Acknowledgement}

We sincerely acknowledge the Research Center for UltraPrecision Science \& Technology, Osaka University for TEM measurements.

Received: ((will be filled in by the editorial staff))

Published online on ((will be filled in by the editorial staff))

Keywords: self-assembly - catalytic ensemble - interparticle mesospaces $\cdot$ spatial arrangement $\cdot$ mesoporous structures

[1] a) J. M. Thomas, Energy Environ. Sci. 2014, 7, 19; b) Z. Han, R. Eisenberg, Acc. Chem. Res. 2014, 47, 2537; c) S. Fukuzumi, K. Ohkubo, T. Suenobu, Acc. Chem. Res. 2014, 47, 1455.

[2] a) M. D. Kärkäs, E. V. Johnston, O. Verho, B. Åkermark, Acc. Chem. Res. 2014, 47, 100; b) J. R. McKone, N. S. Lewis and H. B. Gray, Chem. Mater. 2014, 26, 407.

[3] a) D. G. Nocera, Acc. Chem. Res. 2012, 45, 767; b) M. Wang, L. Chen, L. Sun, Energy Environ. Sci. 2012, 5, 6763.

[4] a) T. Hisatomi, J. Kubota, K. Domen, Chem. Soc. Rev. 2014, 43, 7520 b) B. Viswanathan, V. Subramanian, J. S. Lee, eds., Materials and Processes for Solar Fuel Production, Springer, New York, 2014; c) J. Sa, ed., Fuel Production with Heterogeneous Catalysis, CRC Press, Boca Raton, 2014; d) S. J. A. Moriz, S. A. Shevlin, D. J. Martin, Z. X. Guo, J. W. Tang, Energy Environ. Sci. 2015, 8, 731; e) D. Kim, K. K. Sakimoto, D. Hong, P. Yang, Angew. Chem. Int. Ed. 2014, 53, 2.

[5] a) V. Artero, M. Fontecave, Chem. Soc. Rev. 2013, 42, 2338; b) S. Berardi, S. Drouet, L. Francàs, C. Gimbert-Suriñach, M. Guttentag, C. Richmond, T. Stoll, A. Llobet, Chem. Soc. Rev. 2014, 43, 7501; c) D. Z. Zee, T. Chantarojsiri, J. R. Long, C. J. Chang, Acc. Chem. Res. 2015, 48,
2027; d) L. Cheng, G. Chen, C.-F. Leung, S.-M. Yiu, C.-C. Ko, E. Anxolabéhére-Mallart, M. Robert, T.-C. Lau, ACS Catal. 2015, 5, 356.

[6] S. Roy, M. Bacchi, G. Berggren, V. Artero, ChemSusChem 2015, 8, 3632.

[7] H. Lin, D. Liu, J. Long, Z. Zhang, H. Zhuang, Y. Zheng, X. Wang, Phys. Chemistry Chem. Phys. 2015, 17, 10726.

[8] T. Zhou, Y. Du, A. Borgna, J. Hong, Y. Wang, J. Han, W. Zhang, R. Xu, Energy Environ. Sci. 2013, 6, 3229.

[9] (a) M. Zhu, Z. Li, Y. Du, Z. Mou, P. Yang, ChemCatChem 2012, 4, 112. (b) M. Zhu, Y. Dong, Y. Du, Z. Mou, J. Liu, P. Yang, X. Wang, Chem.Eur. J. 2012, 18, 4367.

[10] T. Yu, W. Wang, J. Chen, Y. Zeng, Y. Li, G. Yang, Y. Li, J. Phys. Chem. C 2012, 116, 10516

[11] T. Arai, S. Matsumoto, N. Obata, T. Kato, N. Nishino, Photochem. Photobiol. Sci. 2012, 11, 289

[12] J. Hong, Y. Wang, J. Pan, Z. Zhong, R. Xu, Nanoscale 2011, 3, 46554661.

[13] a) X. Zhang, Z. Jin, Y. Li, S. Li, G. Lu, J. Phys. Chem. C 2009, 113, 2630; b) X. Zhang, Z. Jin, Y. Li, S. Li, G. Lu, J. Power Sources 2007, 166,74 .

[14] a) A. J. Cowan, J. R. Durant, Chem. Soc. Rev. 2013, 42, 2281; b) S. Fukuzumi, Curr. Opin. Chem. Biol. 2015, 25, 18.

[15] S. Fukuzumi, H. Kotani, K. Ohkubo, S. Ogo, N. V. Tkachenko, H. Lemmetyinen, J. Am. Chem. Soc. 2004, 126, 1600.

[16] H. Kotani, K. Ohkubo, S. Fukuzumi, Faraday Discuss. 2012, $155,89$.

[17] a) H. Kotani, K. Ohkubo, Y. Takai, S. Fukuzumi, J. Phys. Chem. B 2006, 110, 24047; b) H. Kotani, R. Hanazaki, K. Ohkubo, Y. Yamada, S. Fukuzumi, Chem. Eur. J. 2011, 17, 2777.

[18] a) S. Fukuzumi, Y. Yamada, T. Suenobu, K. Ohkubo, H. Kotani, Energy Environ. Sci. 2011, 4, 2754; b) S. Fukuzumi, D. Hong, Y. Yamada, J. Phys. Chem. Lett. 2013, 4, 3458.

[19] a) Y. Yamada, T. Miyahigashi, H. Kotani, K. Ohkubo, S. Fukuzumi, J. Am. Chem. Soc. 2011, 133, 16136; b) Y. Yamada, T. Miyahigashi, H Kotani, K. Ohkubo, S. Fukuzumi, Energy Environ. Sci. 2012, 5, 6111; c) Y. Yamada, T. Miyahigashi, K. Ohkubo, S. Fukuzumi, Phys. Chem. Chem. Phys. 2012, 14, 10564.

[20] Y. Yamada, A. Nomura, K. Ohkubo, T. Suenobu, S. Fukuzumi, Chem. Commun. 2013, 49, 5132.

[21] Y. Yamada, S. Shikano, S. Fukuzumi, J. Phys. Chem. C 2013, 117, 13143.

[22] a) Y. Yamada, H. Tadokoro, S. Fukuzumi, RSC Adv., 2013, 3, 25677; b) Y. Yamada, A. Nomura, H. Tadokoro, S. Fukuzumi, Catal. Sci. Technol. $\mathbf{2 0 1 5}, 5,428$

[23] J. Canning, M. Ma, B. C. Gibson, J. Shi, K. Cook, M. J. Crossley, Opt. Mater. Express 2013, 3, 2028.

[24] a) M. Naqshbandi, J. Canning, B. C. Gibson, M. M. Nash, M. J. Crossley, Nat. Commun. 2012, 3, 1188; b) J. Canning, G. Huyang, M. Ma, A. Beavis, D. Bishop, K. Cook, A. McDonagh, D. Shi, G.-D. Peng, M. J. Crossley, Nanomaterials 2014, 4, 157.

[25] T. Y. Nara, H. Togashi, S. Ono, M. Egami, C. Sekikawa, Y. Suzuki, I. Masuda, J. Ogawa, N. Horinouchi, S. Shimizu, F. Mizukami, T. Tsunoda, J. Mol. Catal. B 2011, 68, 181.

[26] K. S. W. Sing, D. H. Everett, R. A. W. Haul, L. Moscou, R. A. Pierotti, J. Rouquerol, T. Siemieniewska, Pure Appl. Chem. 1985, 57, 603. 
Entry for the Table of Contents

\section{Photocatalysis}

Yusuke Yamada, ${ }^{*}$ Hideyuki Tadokoro, Masood Naqshbandi, John Canning, ${ }^{*}$ Maxwell J. Crossley, ${ }^{*}$ Tomoyoshi Suenobu, and Shunichi Fukuzu$\mathrm{mi}^{*}$ Page - Page

An assembly of nearly monodispersed $\mathrm{Al}^{3+}$-doped $\mathrm{SiO}_{2}$ nanoparticles (20-30 $\mathrm{nm})$ possessing interparticle mesospaces is suitable for incorporating Pt nanoparticles and an organic photocatalyst (2phenyl-4-(1-naphthyl)quinolinium ion) acts as an efficient composite catalyst for

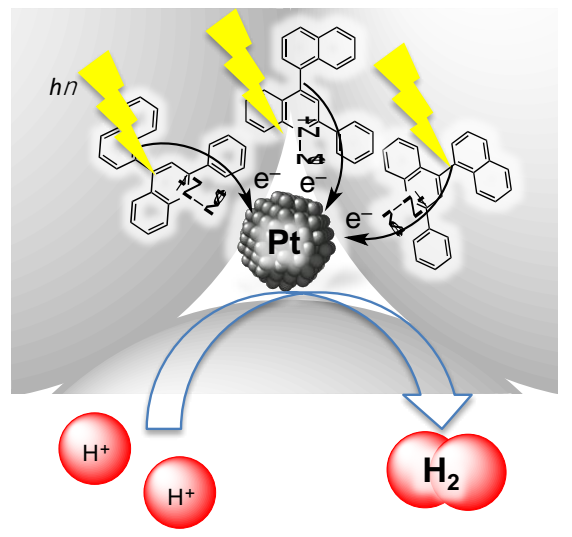
photocatalytic $\mathrm{H}_{2}$ evolution. 